\title{
Leonilson: uma obra biográfica ou política?'
}

\author{
Aline Siqueira Cordeiro" e André "Sheik" Fernandes Leite da Luz"I \\ Resumo: Partindo de Leo não consegue mudar o mundo, texto de Fabrícia Jordão publicado em 2021, o \\ presente artigo compara as provocações feitas pela autora sobre a análise hegemônica da obra do artista \\ cearense Leonilson com textos críticos e outras fontes produzidas em diferentes períodos.t
}

Palavras-chaves: Leonilson. Micropolítica. Arte e vida. Aids.

\section{Leonilson: a biographical or political body of work?}

\begin{abstract}
Starting from Leo não consegue mudar o mundo (Leo can't change the world), a text written by Fabrícia Jordão and published in 2021, the present paper compares the provocations made by the author about the hegemonic analysis of the artworks of Ceará-born artist Leonilson with critical texts and other sources produced in different periods.
\end{abstract}

Keywords: Leonilson. Micropolitics. Art and life. AIDS.

I Este artigo foi realizado no âmbito do projeto "História da Arte Global" do Programa de Pós-Graduação em História da Arte da UERJ, que conta com apoio financeiro da FAPERJ (Edital n. 12/2019).

il Pesquisadora do Museu de Arte Moderna do Rio de Janeiro (MAM Rio). Mestranda em História da Arte pelo Programa de Pós-Graduação em História da Arte da Universidade do Estado do Rio de Janeiro (UERJ). Bacharel em História da Arte pela mesma instituição. Discente da Universidade do Estado do Rio de Janeiro - R. São Francisco Xavier, 524 - Maracanã, Rio de Janeiro - RJ, 20550-013. E-mail: alinesiqueira.c@gmail.com. ORCID: https://orcid. org/0000-0002-1095-9202. Lattes iD: http://lattes.cnpq.br/3604846119871336. Rio de Janeiro, Brasil.

III Artista, curador, poeta e músico. Mestrando em História da Arte pelo Programa de Pós-Graduação em História da Arte da Universidade do Estado do Rio de Janeiro (UERJ). Bacharel em História da Arte pela mesma instituição. Bolsista FAPERJ. Discente da Universidade do Estado do Rio de Janeiro - R. São Francisco Xavier, 524 - Maracanã, Rio de Janeiro - RJ, 20550-013. E-mail: sheik@sheik.com.br. ORCID: https://orcid.org/0000-0001-5962-3243. Lattes iD: http://lattes.cnpq.br/7756052773142235. Rio de Janeiro, Brasil. 
Em março de 2021, a revista Cult publicou o artigo Leo não consegue mudar o mundo, de autoria da pesquisadora Fabrícia Jordão. O título é uma apropriação do nome de uma pintura de Leonilson ${ }^{1}$, o que a autora repete no decorrer do texto e que afirma ser essencial para embasar seus argumentos. A escolha da frase provoca a reflexão do leitor e corrobora a afirmativa de Jordão de que a apreciação crítica da produção do artista mantém em segundo plano seu caráter político e dá destaque a características autobiográficas e confessionais. Para ela, ao elegerem a perspectiva teórica de cunho pessoal como a narrativa principal da obra de Leonilson, os autores muitas vezes apresentam os trabalhos do artista como proposições despolitizadas. Entretanto, Jordão não cita os nomes aos quais se refere para fazer essa afirmação.

Sua leitura nos despertou o interesse em retornar a alguns artigos sobre o artista divulgados em publicações produzidas desde a década de 1990, além da produção audiovisual documental sobre sua vida e obra. A análise desses escritos, feitos em temporalidades distintas, e dos depoimentos de Leonilson, somada à problematização feita por Jordão, servem-nos como importante exercício para a elaboração de nossas dissertações².

Ao evocar a discussão do que é político, podemos voltar à concepção aristotélica e pensar que o viver em sociedade faz de todo ser humano um animal político. Assim, tudo o que fazemos tem uma ação sobre a sociedade. Ou reação. Uma dimensão da arte, mesmo que não explícita, pode ser aquela a qual o filósofo Jacques Rancière (2012) se refere em $O$ espectador emancipado: a de reagir às dominações econômica, estatal e ideológica, fornecendo uma resposta por vezes discordante, não aderente, dissonante. Para Rancière, o dissenso que a arte opera já é uma atitude política, no sentido de que arte e política são maneiras de reconfigurar a experiência comum do sensível. Para o autor, "a eficácia da arte não consiste em transmitir mensagens, dar modelos ou contramodelos de comportamento ou ensinar a decifrar as

1 José Leonilson Bezerra Dias nasceu em Fortaleza, no Ceará, em 1957, e morreu na capital paulista, em 1993, em decorrência de complicações da Aids.

2 Aline Siqueira é mestranda da linha de Arte e Recepção e orientada pela Prof. ${ }^{a}$ Dra. Fernanda Pequeno da Silva. Sua pesquisa, que aborda a representação da Aids nas artes visuais, debruça-se sobre a obra de Leonilson e Félix González-Torres. O estudo aponta fatores que influenciaram as produções dos primeiros anos da década de 1990 em um circuito envolto em narrativas pessoais de artistas enquanto sujeitos soropositivos. Em sua pesquisa de mestrado, também na linha de Arte e Recepção e orientada pelo Prof. Dr. Alexandre Ragazzi, André Sheik analisa artistas relacionando suas produções às suas personalidades. Em um dos agrupamentos, trata de artistas que se utilizam da arte para expressar e, em certo grau, lidar com suas questões emocionais e existenciais. 
representações"3. Segundo ele, há uma lógica dos corpos que faz uma distribuição do comum e do privado, do visível e do invisível, da palavra e do ruído.

Há, a respeito da produção de Leonilson, muitos textos críticos e também, facilmente disponíveis publicamente, fontes com declarações do próprio artista falando sobre seu trabalho. Nesse material, pode-se constatar a íntima relação entre sua vida e sua obra. O artista é o quarto de cinco filhos de uma família de tradição católica e, em sua formação, frequentou colégios ligados a essa religião. A exposição coletiva inaugural de sua carreira foi em 1977 (ainda durante os seus estudos de artes) e, em 1980, realizou sua primeira individual, Cartas a um amigo, no Museu de Arte Moderna da Bahia.

Em 1982, vendeu trabalhos para importantes galeristas do Rio de Janeiro e de São Paulo e teve sua obra exposta na Art Basel, prestigiada feira internacional de arte. Leonilson participou da emblemática coletiva Como vai você, Geração 80?, em 1984, na Escola de Artes Visuais do Parque Lage, no Rio de Janeiro. Contudo, o artista é considerado um outsider dessa geração, principalmente em função do forte aspecto biográfico de sua produção.

Obras suas estão em importantes coleções no Brasil e no exterior, em instituições como o Museu de Arte Moderna do Rio de Janeiro, Museu de Arte Contemporânea da Universidade de São Paulo, Museu de Arte Contemporânea de Niterói, Museum of Modern Art, em Nova lorque, EUA, Centre Georges Pompidou, Paris, França, e Tate Modern, Londres, Inglaterra, para citar apenas algumas ${ }^{4}$. Leonilson teve uma carreira profícua, deixando cerca de 4.000 obras $^{5}$, além de vasto acervo documental.

No livro Leonilson: são tantas as verdades, publicação ligada à exposição homônima sediada na Galeria de Arte do SESI, São Paulo, a curadora e crítica de arte Lisette Lagnado faz sua própria divisão da trajetória do artista. Ela destaca três núcleos formativos:

[...] os primeiros anos (1983-88) buscam uma definição estética por meio do "prazer

3 RANCIÈRE, Jacques. Paradoxos da arte política. In: RANCIÈRE, Jacques. O espectador emancipado. São Paulo: Martins Fontes, 2012. p. 55.

4 Uma lista mais detalhada pode ser encontrada no site do Projeto Leonilson. Disponível em: https://projetoleonilson.com.br/conteudo.aspx?id=4\&ids=3\&seq=0. Acesso em: 5 jun. 2021.

5 De acordo com o site do Projeto Leonilson. Disponível em: https://projetoleonilson.com.br/ conteudo.aspx?id=2\&ids=1\&seq=0. Acesso em: 13 jun. 2021. 
da pintura"; em seguida (1989-91), o artista encontra um ponto de firmeza no tema do "abandono" e na sua inclinação para os valores românticos; nos dois últimos anos de sua vida, a alegoria da doença domina por completo a linguagem. ${ }^{6}$

Resumidamente, a primeira fase é a época da chamada volta à pintura. Há um boom no mercado de arte, com valorização das telas que transmitem "uma mensagem alegre, colorida e irônica"7. No segundo momento da produção, Leonilson trabalha mais com desenhos bordados em tecidos. Já entre 1990 e 1993, "a pintura se torna quase monocromática, com pequenos desenhos sobre uma única cor, profunda e ativa" ${ }^{8}$, e a Aids, nos dois últimos anos de sua vida, é o principal tema.

A urgência da chamada "Geração 80", esse movimento antes alegre, de cores sem compromisso, tornou-se um fardo trágico no qual urgência agora é sinônimo de morte - donde a ambivalência que imprime no seu autor o sentimento de ser algoz de si mesmo. ${ }^{9}$

A leitura contemporânea não exclui o viés de Lagnado, predominantemente biográfico. No documentário Leonilson, sob o peso dos meus amores (2012), de Carlos Nader, todos os testemunhos - de curadores e artistas que com Leonilson conviveram - são unânimes em relacionar sua vida com sua arte, e vice-versa. O próprio artista diz: "Para viver, eu preciso pintar. A vida e a arte faz [sic] parte do salto no abismo que eu resolvi dar"10. Em entrevista realizada em 1993, ao falar sobre sua produção recente, Leonilson declara: "Estes trabalhos são a minha autobiografia. Eles são o meu diário"11.

Em suas pinturas, desenhos e bordados, Leonilson acrescenta palavras e frases, elementos que auxiliam na criação de seu imaginário poético e comunicam as mensagens existentes em seus trabalhos. Ainda, a partir da repetição de símbolos, Leonilson imprime metáforas sociais sobre as relações humanas, o mundo e sobre si mesmo. A natureza autobiográfica de sua obra abre-se para a compreensão da arte como conhecimento do mundo. Suas

6 LAGNADO, Lisette. O pescador de palavras. In: LAGNADO, Lisette. Leonilson: são tantas as verdades. São Paulo: Projeto Leonilson: SESI, 1995. p. 29.

7 LAGNADO, Lisette. O pescador de palavras. In: LAGNADO, 1995, p. 30.

8 LAGNADO, Lisette. O pescador de palavras. In: LAGNADO, 1995, p. 37.

9 LAGNADO, Lisette. O pescador de palavras. In: LAGNADO, 1995, p. 51.

10 LEONILSON, sob o peso dos meus amores. Direção de Carlos Nader. São Paulo: Instituto Itaú Cultural, 2012. 1 vídeo (42 min). Documentário. Disponível em: https://www.youtube.com/watch?v=8TKHN2LcChA. Acesso em: 21 maio 2021.

11 LEONILSON, sob o peso dos meus amores, 2012. 
experiências fazem parte de uma conjuntura sociocultural, e por isso não podem ser entendidas apenas como questões isoladas, exclusivas do artista.

Mesmo Lisette Lagnado (1995) - ainda que priorize discorrer sobre os aspectos pessoais na obra de Leonilson - expõe a consciência política do artista em razão da sua homossexualidade e, nesse momento final de sua vida, também por ser portador do vírus HIV.

Eu sou uma pessoa perigosa no mundo. Ninguém pode me beijar. Se eu me corto, ninguém pode cuidar dos meus cortes. Eu tenho que ir numa clínica. Tem gente perigosa porque tem uma arma na mão. Eu tenho uma coisa dentro de mim que me torna perigoso. Não preciso de arma. Basta me cortar. Veja os caras nas prisões com HIV positivo: eles se cortam e ficam ameaçando contaminar os outros. ${ }^{12}$

A constatação feita pela citação acima é expressa na série $O$ Perigoso, de 1991, composta por sete desenhos feitos durante uma das internações de Leonilson enquanto se recuperava de uma pneumonia. O primeiro trabalho da série traz, na folha branca, uma pequena gota de seu sangue coagulado acompanhada da inscrição do título da obra. Os demais têm pequenos desenhos, ora com representações de situações cotidianas resultantes da doença - como frasco de comprimidos, coleta de sangue e aplicação de medicação venosa -, ora com referências ao catolicismo por meio de inscrições e representações de objetos religiosos.

Durante uma sequência de sete encontros realizados entre outubro e dezembro de $1992^{13}$, Leonilson e Lagnado comentaram sobre a ironia existente no primeiro desenho, ao propor a desmistificação de algo grandioso como única fonte de poder e apresentar uma gota de sangue como perigosa. Para o artista, a infecção pelo HIV o transformou, por menor e mais fraco que se sentisse, na pessoa mais perigosa do mundo naquele momento.

Voltando ao texto de Fabrícia Jordão (2021), a autora localiza o leitor no contexto social vivido por Leonilson, com destaque para a situação política da época. Abertura lenta, gradual e segura, fim da ditadura, Geração 80 e epidemia da Aids são os termos que preenchem essa recapitulação. Jordão salienta que o cenário no qual se inscrevem os primeiros anos da produ-

12 LEONILSON. A dimensão da fala. [Entrevista cedida a] Lisette Lagnado. In: LAGNADO, 1995, p. $123-124$

13 LEONILSON. A dimensão da fala. [Entrevista cedida a] Lisette Lagnado. In: LAGNADO, 1995, p. 76-136. 
Figura 1

Leonilson. O perigoso

(da série $O$ perigoso),

1992. Tinta de caneta permanente e sangue sobre papel, $30,5 \times 23$

$\mathrm{cm}$. Projeto Leonilson, Rubens Chiri.

ção de Leonilson coincide com o fim do "ideário ético, político e estético utópico-revolucionário"14 representado pela arte conceitual produzida no período ditatorial. A autora declara que, após a abertura política, o artista é um daqueles que recuperam a poesia que ficou oculta nos anos 1960 e 1970 devido ao medo causado pela repressão militar.

Jordão destaca ainda que a produção dos últimos anos da vida do artista é a mais abordada em publicações e curadorias. O período compreendido entre agosto de 1991, com a descoberta de sua soropositividade, e maio de 1993, quando morre em decorrência da Aids, é aquele de maior fragilidade física de Leonilson e caracterizado pela mudança da temática e do suporte, levando à produção de trabalhos em menor escala. 
$\mathrm{Na}$ época em que a gente fazia pinturas grandes, eu achava que a gente tinha que usar a violência, a força, mas agora acho tudo aquilo muito babaca. É preciso passar por isso tudo para chegar num paninho como este. ${ }^{15}$

Foi sobre um recorte desse período final que o crítico de arte Ivo Mesquita (2006) se debruçou em Corpo vidente, corpo visível, publicado no livro Leonilson: use, é lindo, eu garanto ${ }^{16}$. A publicação trata das ilustrações feitas por Leonilson de 1991 a 1993 para a coluna Talk of the town, da jornalista Barbara Gancia, do jornal Folha de S. Paulo. As imagens eram desenvolvidas a partir do tema da coluna da semana, sem que o artista tivesse conhecimento da totalidade do texto, o que permitia certa autonomia para o desenho. Foi por esse canal que Leonilson fez críticas mais severas ao governo e à sociedade da época.

No ano de 2020, Ivo Mesquita revisitou seu texto para o catálogo da exposição europeia Leonilson, Drawn 1975-1993 ${ }^{17}$. No novo ensaio, intitulado Vivid Body, Visible Body: Revisited, o autor expõe que, apesar dessas ilustrações serem datadas e refletirem sobre a situação política e econômica do Brasil durante o governo Fernando Collor de Mello (1990-92), suas representações muito se assemelham ao cenário nacional de hoje:

[...] não se pode deixar de notar as semelhanças e a persistência de certos temas debatidos. Há pilares da cultura política, econômica e social do país que reaparecem com o tempo, fazendo com que os desenhos da Folha de S. Paulo continuem relevantes e criticamente poderosos. ${ }^{18}$

O autor argumenta ser possível encontrar ao menos um desenho de Leonilson para ilustrar cada característica do atual governo federal, tais sejam: autoritário, clientelista, negligente, violento. Um governo que promove,

16 MESQUITA, Ivo. Corpo vidente, corpo visível. In: LEONILSON: use, é lindo, eu garanto. 2. ed. São Paulo: Cosac Naify, 2006. p. 11-16. O ano de 2006 refere-se à segunda edição do livro, originalmente publicado em 1996.

17 A exposição, atualmente em exibição no Malmö Konsthall, em Malmö, na Suécia, já passou pelo KW Institute for Contemporary, em Berlim, na Alemanha, e tem itinerância prevista ainda para a Fundação de Serralves, no Porto, em Portugal.

18 MESQUITA, Ivo. Vivid body, Visible Body: Revisited. In: GRUIJTHUIJSEN, Krist (Ed.). Leonilson: Drawn 1975-1993. Berlin: Hatje Cantz, 2020. p. 221. (Tradução nossa) No original: [...] one cannot fail to notice the similarities and persistence of certain debated issues. There are mainstays of the country's political, economic, and social culture that reappear over time, meaning that the drawings from the Folha de São Paulo remain relevant and critically powerful. 
segundo ele, ataque aos princípios democráticos e às instituições; discriminação contra minorias étnicas, sexuais e religiosas; obscurantismo em relação à educação e à cultura; devastação do meio ambiente e de populações indígenas e quilombolas. Ele comenta ainda que o maior lamento não é apenas a repetição do quadro social daquela época, mas a incapacidade de superação e a falta de soluções efetivas para os mesmos problemas de antes.

Para Mesquita, os desenhos do jornal revelam um cidadão do mundo, engajado, um indivíduo comprometido com seu tempo e seu lugar. Assim, eles podem ser, simultaneamente, pessoais e políticos, ainda que as imagens variem, de acordo com o autor, entre o banal e o manifesto, pois, segundo ele, responderiam, de forma direta e ampla, à época em que o artista viveu, transformando em um espaço de ativismo a prática artística de Leonilson. As observações a respeito do mundo feitas pelo artista (um observador afiado e sofisticado), sua perspectiva, tudo era registrado como em um diário (uma de suas práticas) em seus desenhos, que funcionam como crônicas do período. Suas sensações e seus sentimentos são como críticas mordazes e provocativas, segundo o autor.

Mesquita faz uma leitura simbólica de alguns elementos dos trabalhos de Leonilson que apontam a dimensão política da obra do artista. Para ele, o pódio, por exemplo:

[...] serve como uma metáfora para a estrutura social; desigualdade e injustiça; o abuso de poder; a pilhagem da esfera pública e o desrespeito ao cidadão comum; e a corrida pelo status de dinheiro e fama. ${ }^{19}$

Assim como suas imagens de figuras, de casas e de carros sobre palafitas, o pódio não seria, para Mesquita, somente símbolo de triunfo econômico e social, "mas também um sinal irônico de deterioração política e moral, frivolidade, consumismo, esnobismo e a vaidade de cultura urbana globalizada" ${ }^{20}$.

A dimensão ética das obras feitas para a Folha de S. Paulo estaria em produzir ambiguidades e desafiar verdades absolutas por intermédio da visão única

19 MESQUITA, Ivo. Vivid body, Visible Body: Revisited. In: GRUIJTHUIJSEN, 2020, p. 226. (Tradução nossa) No original: The podium serves as a metaphor for social structure; inequality and injustice; the abuse of power; the pillaging of the public realm and disrespect for common citizens; and the race for money status, and fame.

20 MESQUITA, Ivo. Vivid body, Visible Body: Revisited. In: GRUIJTHUIJSEN, 2020, p. 226. (Tradução nossa) No original: [...] but also an ironic sign of political and moral deterioration, frivolity, consumerism, snobbery, and the vanity fair of globalized urban culture. 
do artista, seu ponto de vista. Desse modo, seu olhar é político e na obra se revela. As ilustrações passam a ser caricaturas, revelando uma estratégia do artista para expressar opiniões, explicitando um compromisso direto de Leonilson com as questões da arena social e política, na visão de Mesquita.

[...] a figura da doença aparece na coluna pela primeira vez em Os chatos unidos foram enfim vencidos (04 de setembro de 1991), em que cinco xícaras vazias são rotuladas com "os indesejáveis" e "aqueles com veneno" - vítimas da AIDS, povos indígenas, comunistas, ciganos e prostitutas. Depois dessa primeira coluna relacionada à AIDS, o foco do artista se volta para os desprezados e discriminados - os jovens da favela, a comunidade LGBT, os soropositivos e os povos indígenas - que clamam por valores humanitários como compreensão, inclusão e dignidade na busca intensa de sentido na brevidade da vida. ${ }^{21}$

As ilustrações de Leonilson acabam, por vezes, contrapondo-se às opiniões evidenciadas no texto da colunista da Folha de S. Paulo. Associamos essas oposições ao que Jacques Rancière denomina como "um trabalho de ficção"22, porém não como criações inventadas do mundo real, e sim como formas alternativas de apresentação do sensível. Para ele, essa ação também é caracterizada pelo dissenso e causa uma mudança em nossa percepção dos acontecimentos e, consequentemente, em nossa relação com esses sujeitos.

[...] as estratégias dos artistas que se propõem mudar os referenciais do que é visível e enunciável, mostrar o que não era visto, mostrar de outro jeito o que não era facilmente visto, correlacionar o que não estava correlacionado, com o objetivo de produzir rupturas no tecido sensível das percepções e na dinâmica dos afetos. ${ }^{23}$

Fazendo uma divisão da produção de Leonilson em duas fases - antes e depois do diagnóstico de HIV -, é possível ver uma mudança na maneira de pensar do artista através de duas de suas pinturas: Leo não consegue mudar o mundo (1989), que traz seu título escrito na obra; e O Monte das Oliveiras (c. 1992), na qual consta a frase "Leo pode mudar seu mundo". Nos dizeres desses dois trabalhos, observa-se uma espécie de troca de chave nas possibilidades de mudança que Leo se sente capaz de operar.

21 MESQUITA, Ivo. Vivid body, Visible Body: Revisited. In: GRUIJTHUIJSEN, 2020, p. 231-233. (Tradução nossa) No original: [...] the figure of the disease appears in the column for the first time in Os chatos unidos foram enfim vencidos (United bores are finally defeated, September 4, 1991), in which five empty cups are labelled with "the undesirables" and "those with poison" - AIDS victims, Indigenous peoples, communists, gypsies, and prostitutes. After the first AIDS-related column, the artist's focus turns to those dispossessed and discriminated - the shanty-town youth, the LGBT community, the HIV positive, and Indigenous peoples - clamoring for humanitarian values like understanding, inclusion, and dignity in an intense search for meaning within the brevity of life.

22 RANCIÈRE, Jacques. Paradoxos da arte política. In: RANCIÈRE, 2012, p. 64.

23 RANCIÈRE, Jacques. Paradoxos da arte política. In: RANCIÈRE, 2012, p. 64. 
No ano de produção da primeira obra, 1989, diversos acontecimentos marcantes ocorreram no mundo, como a primeira eleição para presidente pós-ditadura no Brasil, a queda do Muro de Berlim na Alemanha, as manifestações na Praça da Paz Celestial na China, para mencionar apenas alguns. Há um forte clima de otimismo no ar, embora a Aids tenha trazido o medo para as relações sexuais. As lutas políticas eram ruidosas. Leo pinta, desenha. Pequenos gestos, ações quase silenciosas.

Em Leo não consegue mudar o mundo (1989), o artista se vê - ou se percebe - impossibilitado de fazer qualquer mudança no mundo, de alterar o desenrolar dos acontecimentos, as injustiças sociais que presencia. Na parte de cima do trabalho, consta a afirmação escrita de que ele não consegue mudar o mundo. Seu coração se encontra, abaixo, sobrevoado pelo "abismo" e pelas "luzes", palavras igualmente pintadas na lona. Essa representação de um coração parece apoiada em um suporte que se bifurca, talvez designando um enraizamento que impede a movimentação desejada. Poderiam também ser vasos conectados ao coração, todavia, essas estruturas, da maneira como estão representadas na pintura, não existem de fato na anatomia humana. Nas faixas brancas, uma para cada lado, está escrito: "inconformado" (à esquerda) e "solitário" (à direita). Assim, Leonilson estaria - ou seria - solitário, inconformado simultaneamente, ou no pulsar do coração. Ou, ainda, dividido entre uma coisa e outra. Na composição do trabalho, as palavras (sobre fundo claro), distribuídas na tela, têm peso igual ao da representação do coração ao centro.

A segunda possibilidade para Leonilson, após o diagnóstico, é mudar a si mesmo ou seu mundo. Ainda que se possa interpretar que o mundo de Leonilson é o de todos nós, nossa leitura é a de que a frase "Leo pode mudar seu mundo" indica uma possibilidade de mudança interior, pessoal. Em O Monte das Oliveiras (c. 1992), as palavras estão quase escondidas, imperceptíveis em relação às figuras representadas (o oposto do outro trabalho analisado) e distribuídas em uma superfície de cor uniforme. As ilustrações não têm um reconhecimento claro, explícito, embora, eventualmente, possam vagamente lembrar objetos reais. Há outros dizeres igualmente quase invisíveis na tela (além do que se refere ao nome do artista): "a consciência", "eu sou", "o firme pensamento", "a palavra viva", "a minha maneira", "o monte das oliveiras".

A forte ligação de Leonilson com a sua criação católica permite a associação de sua obra a componentes da iconografia cristã. Isso pode ser visto nos dois trabalhos apresentados acima e pode ser identificado pela presença do coração e da dicotomia entre "abismo" e "luzes", na primeira, e no próprio título da segunda. O Monte das Oliveiras é uma referência religiosa à região localizada às margens da cidade antiga de Jerusalém, onde, segundo escritos 


\section{LEDNID [DNSEGUE MUDAR UMUNDO}

Figura 2

Leonilson. Leo não consegue mudar o mundo, 1989. Tinta acrílica e tinta metálica sobre lona, $156 \times 95$ $\mathrm{cm}$. Projeto Leonilson, Edouard Fraipont 


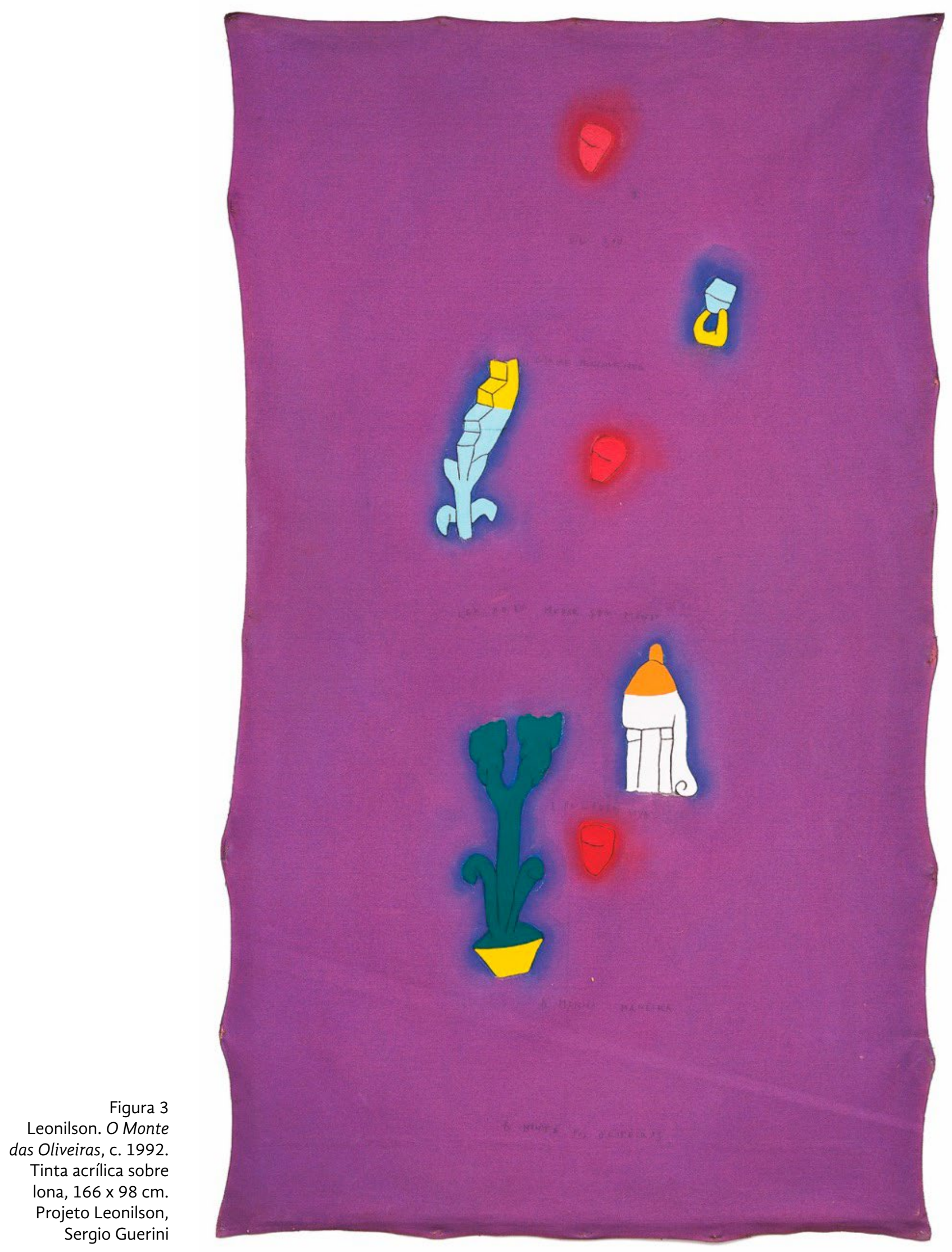


da Bíblia, Jesus teria passado muitos ensinamentos a seus discípulos. Outras alusões ao aprendizado cristão e a esse local sagrado aparecem em As Oliveiras (1990), pertencente ao acervo do Museu de Arte Moderna de São Paulo $^{24}$. Nesse trabalho, há novamente a representação do coração, dessa vez, envolto em inscrições diversas, como sua assinatura e data, algumas frases que parecem trechos de poemas, além de uma extensa lista de substantivos e adjetivos que constituem as relações humanas.

Mesmo a gota de sangue, mencionada anteriormente por compor a obra $O$ Perigoso, pode ser entendida como integrante dessa iconografia, relacionando-se a Jesus Cristo e ao sofrimento da crucificação. Outros nexos podem ser criados sobre o reconhecimento do artista na figura de Cristo como, por exemplo, a brevidade de sua vida e sua sensibilidade com aqueles socialmente excluídos. Ivo Mesquita (2020) aponta que a ameaça da morte, causada pela doença, aproximou o artista dos discriminados, daqueles a quem a sociedade, de um modo geral, dava - e ainda dá - pouco valor.

Mais um ponto de destaque é que, a despeito de serem extremamente pessoais, Leonilson considerava suas peças como significativas para outras pessoas, pois o espectador poderia estabelecer conexões entre suas próprias questões emocionais e as do artista. No filme de Carlos Nader, A Paixão de $J L$ (2015), Leonilson, a certa altura, comentando a respeito da situação do Brasil no começo da década de 1990 - e falando de si mesmo na terceira pessoa -, explicita sua entrega:

Eu acho o máximo, $[\ldots]$ que no meio dessa loucura, $[. .$.$] tem um cara que dedica o$ tempo dele para fazer uma obra de arte, uma coisa delicada [...] entrega o coração dele na mão das pessoas, nos olhos das pessoas. ${ }^{25}$

Contrapondo-se a essa delicadeza, Leonilson retoma também o tema da violência na fase final de sua produção. Porém, diferentemente da literalidade que é parte da criação das pinturas em grandes formatos dos anos 1980, a violência dessa fase é simbólica e exibida no conteúdo. Fabrícia Jordão (2021) cita uma fala de Leonilson sobre a consciência de que mesmo a poesia pode machucar, ao se tratar de algo a respeito do qual que as pessoas não querem ouvir:

24 Doação de Carmem Bezerra Dias e Theodorino Torquato Dias.

25 A PAIXÃO de JL. Direção de Carlos Nader. São Paulo: Instituto Itaú Cultural, 2015. 1 vídeo (82 min). Disponível em: https://www.youtube.com/watch?v=sNUsY1un51w. Acesso em: 21 maio 2021. 
Figura 4

Leonilson. As Oliveiras, 1990. Aquarela, caneta permanente e grafite sobre papel, $25,4 \times 20,1 \mathrm{~cm}$.

Projeto Leonilson, Edouard Fraipont

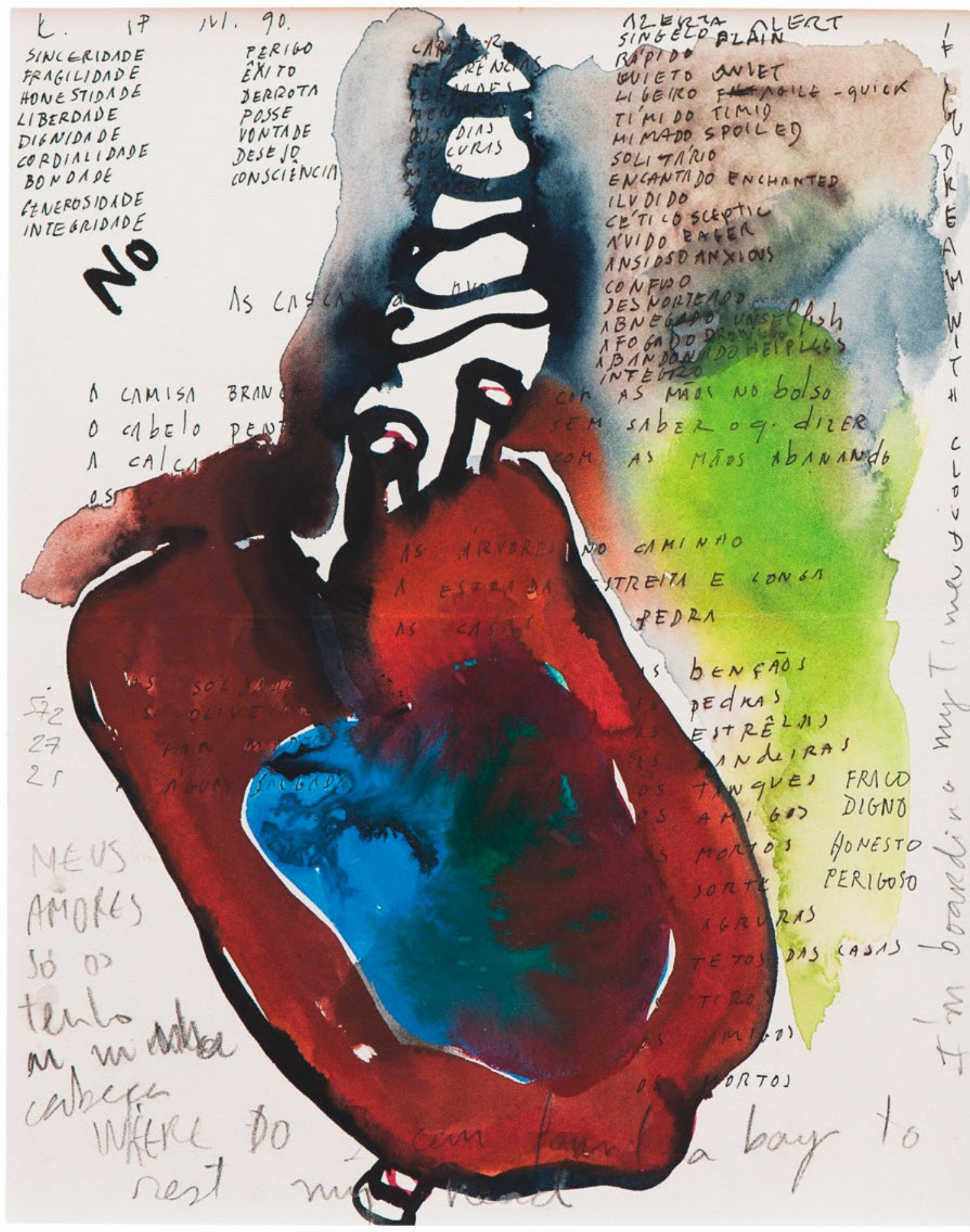

Eu não extravaso com violência, nem com o uso do poder, mas acho que as coisas calminhas cutucam tanto quanto um tiro na testa. Uma poesia gay, para as pessoas, machuca muito. Eu fiz uma poesia de um menino que eu encontrei num avião, você imagina? E contei detalhes... ${ }^{26}$ 
Parte da produção dos últimos dois anos de Leonilson é marcada por expor temas correlatos à finitude da vida e são envoltos em melancolia, solidão e pessimismo. É sobre isso que Ivo Mesquita (1995) comenta em Para o meu vizinho de sonhos, ao expor a influência da crise da Aids na produção artística da época. Contudo, além do viés negativo, o autor enuncia outras possibilidades políticas de ocupação da doença no imaginário do artista contemporâneo:

Tomada por alguns artistas como causa pessoal, como forma de politização da linguagem plástica, o tema da Aids se configura como uma questão de princípio para salvar o corpo erótico dos delírios do conservadorismo e do preconceito. ${ }^{27}$

Em Jordão (2021), a autora chama atenção para a escolha de Leonilson em priorizar relações de afeto, desejo e erotização para a representação de corpos, mesmo no momento mais grave da crise da Aids, contrapondo-se à exibição midiática massiva de indivíduos debilitados em decorrência da doença. Mesmo que a poética do artista não seja militante, a autora defende que sua subjetividade proporciona uma política de afetos e reposiciona o que é ser político na arte.

Rancière (2012) demonstra que nem sempre o ser político apresenta os contornos de revolta e oposição esperados para sua representação. Na disputa entre o que é ou não político na arte, o filósofo propõe uma inversão de perspectiva para entendermos a que modelos correspondem nossas expectativas e nosso juízo para essa análise. Essa construção é a responsável por definir que objetos e sujeitos são socialmente aceitos para a discussão política e quais são as formas de relações que designam uma comunidade política.

Afastando-se desses modelos, o autor então elenca a variação existente nas abordagens adotadas por artistas com o intuito de transmitir uma mensagem que possibilite a tomada de consciência e, para isso, cita exemplos completamente diversificados entre si. Dessa forma, conclui que:

A vontade de repolitizar a arte manifesta-se assim em estratégias e práticas muito diversas. Essa diversidade não traduz apenas a variedade dos meios escolhidos para atingir o mesmo fim. Reflete uma incerteza mais fundamental sobre o fim em vista e sobre a própria configuração do terreno, sobre o que é a política e sobre o que a arte faz. ${ }^{28}$ 
Associado a esse pensamento, podemos observar o trabalho feito por Leonilson para Ano zero km sai por preço de banana, de Barbara Gancia, publicado na coluna Talk of the town de 8 de janeiro de 1992. No texto, a jornalista comenta, de forma pessimista, a chegada do novo ano e, com muita ironia, faz uma rápida retrospectiva de 1991 e sugere possíveis previsões para os meses que viriam. Na ilustração, Leonilson desenha uma escada que termina de forma brusca, indicando uma queda, e que traz no último degrau a inscrição: "ano q. vem". Abaixo da escada aparecem as seguintes frases: "honestidade não dói", "dignidade não fere", "namorar faz bem".

A escada pode ser compreendida como a trajetória do artista, um símbolo para a sua própria história, o que faz com que o final do percurso, a queda, possa ser uma alusão ao fim. Nessa leitura, de forma premonitória - tendo em vista que faleceu no ano seguinte -, o artista indicaria a aproximação de sua morte, porém a previsão não parece amedrontá-lo, considerando as inscrições otimistas que aparecem no desenho em forma de conselho. A menção às palavras "honestidade" e "dignidade" - que também aparecem na obra As Oliveiras (1990) - pode ser vista como outra referência à simbologia cristã, devido à presença de conceitos que são parte dos escritos religiosos. Além do mais, as frases compostas por essas palavras e dispostas na parte inferior do trabalho parecem indicar a ausência de arrependimentos e a autoafirmação de seu percurso de vida.

Durante toda a sua produção, o artista demonstrou-se interessado pelo corpo humano, por anatomia e por metáforas para o amor. No momento em que o medo da Aids tentava aprisionar o comportamento sexual livre idealizado nas décadas anteriores, ao inserir em seu trabalho a mensagem "namorar faz bem", o artista busca subverter a negação do corpo e da sexualidade, privações ocasionadas pelo conservadorismo em torno da doença.

Seu trabalho empenha-se, a partir de então, em desmascarar as regras, os tabus, os constrangimentos e os limites das injunções morais impostos ao corpo e ao desejo. ${ }^{29}$

Hoje, expressões identitárias vêm ganhando maior visibilidade dentro do circuito de arte, resultando em mais produções que se relacionam a essas questões. O externar das individualidades, mesmo quando em pautas coletivas, adquire um estágio de reconhecimento que antes não era tão incorporado 
Figura 5

[Ano zero $\mathrm{km}$ sai por preço de banana], 1992. Tinta de caneta permanente sobre papel, $18 \times 12,5 \mathrm{~cm}$. Projeto Leonilson, Eduardo Ortega

$r$
$m$
$c$
$z$
$z$
$z$
0
$i$

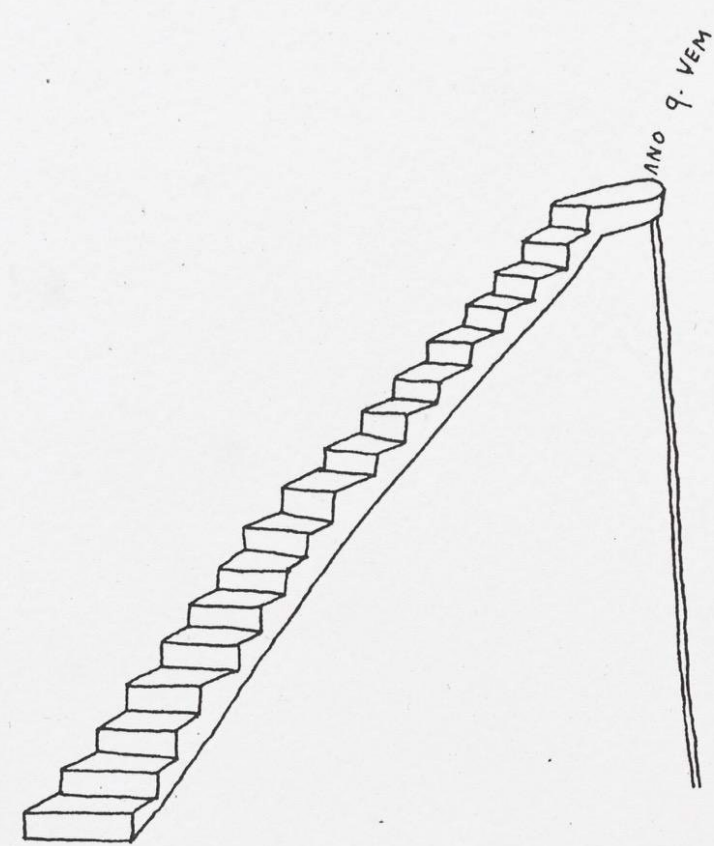

HONESTIDADE NT̃OO DÓI

DIGNIDADE NIOO FERE

NAMORAR FNZ BEM

pelo sistema de arte. As variadas lutas políticas têm novos contornos e, por vezes, são mais explícitas, inclusive na arte.

Ninguém tem monopólio sobre o discurso a respeito de um trabalho de arte. A leitura da obra de um artista está aberta a diversas perspectivas, que podem variar a cada época. Semelhantemente, o posicionamento político, ao longo do tempo, manifesta-se de formas diferentes. A maneira como os temas eram tratados por Leonilson em sua produção talvez não fosse vista, à época, como explicitamente engajada. O que não significa que uma releitura atual, sob o olhar contemporâneo, não possa atentar para um caráter político.

Após analisarmos as visões dos autores abordados e colocá-las frente à perspectiva apontada por Fabrícia Jordão, para responder à pergunta apresentada pelo título, podemos fazer uma inversão da hipótese e concluir: biográfica e política, essa é a obra de Leonilson. 


\section{Referências}

A PAIXÃO de JL. Direção de Carlos Nader. São Paulo: Instituto Itaú Cultural, 2015. 1 vídeo (82 min). Disponível em: https://www.youtube.com/watch?v=sNUsY1un51w. Acesso em: 21 maio 2021.

JORDÃO, Fabrícia. Leo não consegue mudar o mundo. Cult, São Paulo, ano 24, ed. 267, p. 37-39, mar. 2021.

LAGNADO, Lisette. O pescador de palavras. In: LAGNADO, Lisette. Leonilson: são tantas as verdades. São Paulo: Projeto Leonilson: SESI, 1995. p. 26-76.

LEONILSON. A dimensão da fala. [Entrevista cedida a] Lisette Lagnado. In: LAGNADO, Lisette. Leonilson: são tantas as verdades. São Paulo: Projeto Leonilson: SESI, 1995. p. 76-136.

LEONILSON, sob o peso dos meus amores. Direção de Carlos Nader. São Paulo: Instituto Itaú Cultural, 2012. 1 vídeo (42 min). Documentário. Disponível em: https://www.youtube.com/watch?v=8TKHN2LcChA. Acesso em: 21 maio 2021.

MESQUITA, Ivo. Corpo vidente, corpo visível. In: LEONILSON: use, é lindo, eu garanto. 2. ed. São Paulo: Cosac Naify, 2006. p. 11-16.

MESQUITA, Ivo. Para o meu vizinho de sonhos. In: LAGNADO, Lisette. Leonilson: são tantas as verdades. São Paulo: Projeto Leonilson: SESI, 1995. p. 192-197.

MESQUITA, Ivo. Vivid body, Visible Body: Revisited. In: GRUIJTHUIJSEN, Krist (Ed.). Leonilson: Drawn 1975-1993. Berlin: Hatje Cantz, 2020. p. 219-255.

RANCIÈRE, Jacques. Paradoxos da arte política. In: RANCIÈRE, Jacques. $O$ espectador emancipado. São Paulo: Martins Fontes, 2012. p. 51-81. 